\title{
O corpo, a cirurgia estética e a Saúde Coletiva: um estudo de caso
}

\author{
Body, aesthetic surgery and public health: a case study
}

Virginia Costa Lima Verde Leal ${ }^{1}$

Ana M aria Fontenelle Catrib ${ }^{1}$

Rosendo Freitas de Amorim ${ }^{1}$

M iguel Ângelo M ontagner ${ }^{2}$

${ }^{1}$ Programa de Pós-

graduação em SaúdeColetiva, Universidade deFortaleza.

Av. Washington Soares 1321,

Edson Queiroz. 60811-905

FortalezaCE.

virginialimaverde@hotmail.com

2Programa de Pós-

graduação em Ciências da

Saúde, FaculdadedaSaúde,

Universidade de Braślia.
Abstract The body, in the occidental culture, was for many centuries rejected, feared and devaluated; today, differently, it is super valued and became a precious good, for this reason it is well-taken care of and shaped, due to successes and virtues of the individual contemporary being attributed to it. In the search for an ideal body, many people look for aesthetic surgeries as solution for their problems and improvement of their self-esteem. This article aims to understand the relation of the aesthetic surgery with the Public $\mathrm{H}$ ealth and the promotion of health. We carried out a qualitative study, using the case study method, with the objective of understanding the underlying beliefs, attitudes, perceptions and cultural processes to the narratives of the college's students submitted to aesthetic surgery and of the plastic surgeons. The results demonstrate that the body must be understood as something more complex than the physical and visible body, because many of those who look for aesthetic surgery continue unsatisfied, see ing that their dissatisfactions attributed to their body are also a matter of them being attributed to their soul. We conclude that aesthetic beauty is becoming medical subject and that aesthetic surgery is a question of public health, as the results depend on the motivations and expectations of who searches for this procedure.

Key words Body, Aesthetic surgery, Health promotion, Case study, Adverse effects
Resumo 0 corpo, na cultura ocidental, foi por muitos sécul os rechaçado, temido e desvalorizado; hoje, diferentemente, é supervalorizado e tornouse um bem precioso. Por este motivo, é cuidado e modelado, pois a ele são atribuídos os sucessos e as virtudes do indivíduo contemporâneo. $\mathrm{Na}$ busca de um corpo ideal, muitos procuram cirurgias estéticas como solução de insatisfações e melhoria da auto-estima. Este artigo procurou compreender a relação da cirurgia estética com a SaúdeC ol etiva e a promoção da saúde. Realizamos um estudo qualitativo, usando o método do estudo de caso, com o objetivo de compreender as crenças, as atitudes, as percepções e os processos culturais subjacentes às narrativas das universitárias submetidas à cirurgia estética e dos cirurgiões plásticos. Os resultados demonstram que o corpo deve ser entendido como algo mais complexo do que o corpo físico e visível, pois muitos que buscam a cirurgia estética continuam insatisfeitos, visto quesuasinsatiffações atribuídas ao físico são também da alma. Concluímos que existe uma medicalização da beleza estética e que a cirurgia é uma questão de Saúde Coletiva, pois os resultados dependem das motivações e expectativas de quem procura este procedimento. Palavras-chave Corpo, Cirurgia estética, Promoção da saúde, Estudo de caso, Efeitos adversos 
A cirurgia plástica encerra uma finalidade transcendente, que éa tentativa da harmonização do corpo com o espírito, da emoção com o raciocínio, visando estabelecer um equilíbrio interno que permita ao paciente reencontrar-se, reestruturarse, para que sesinta em harmonia com sua própria imagem e com o universo que o cerca.

Ivo Pitanguy ${ }^{1}$

\section{Introdução}

A cirurgia éo ramo da medicina especializada no tratamento de deformidades, lesões ou doenças externas ou internas realizadas por meio de operações. No contexto das possibilidades cirúrgicas, encontra-se a cirurgia plástica, que tem por finalidade a reconstituição artificial de uma parte do corpo². A cirurgia plástica édividida em cirurgia reparadora e estética, tendo a primeira a finalidade de recuperar a função e restaurar a forma ocasionada por alguma enfermidade, traumatismo ou defeito congênito. A cirurgia do tipo esté tica objetiva o embelezamento pela melhora da forma. Entretanto, existe uma dificuldade de um delineamento preciso entre as duas cirurgias, visto que ambas almejam alcançar o equilíbrio da estrutura corporal com a finalidade de uma unidade estética².

Atualmente, o Brasil apresenta-se como um dos campeões mundiais em números de cirurgias estéticas, tendo sido realizadas em 2004 mais de 600.000 cirurgias plásticas; dentre elas, $59 \%$ eram exclusivamenteestéticas, deacordo com a Sociedade Brasileira de Cirurgia Plástica. Isto coloca 0 Brasil como uma referência quanto ao assunto cirurgia estética e o Ceará está entre os dez estados brasileiros com o maior número de intervenções.

Este tipo de cirurgia vem sendo popularizado, deixando de ser um procedimento restrito à classe alta. A busca por procedimentos cirúrgicos vem aumentando no público masculino; no entanto, ainda é o sexo feminino que compõe quasea totalidade dosnúmeros de cirurgias, cerca de $90 \%$, e os procedimentos mais procurados abrangem lipoaspiração, prótese e redução mamária, plástica de abdômen e rejuvenescimento da face. Estas mulheres têm, em geral, entretrinta e quarenta anos; contudo, a procura por parte de adolescentes tem mais crescido nos últimos dez anos. As cirurgias masculinas compreendem um número menor, principalmente correção de cal vície, lipoaspiração erejuvenescimento da face.

De acordo com a Sociedade Brasileira de Cirurgia Plástica, no ano de 1984, apenas $5 \%$ das pessoas que fizeram cirurgia estética tinham menos de dezoito anos. Em 2007, 15\% destepúblico têm menos de dezoito anos, dados que são do conhecimento dasjovens quesesubmetem a procedimentos cirúrgicos.

Reconhecemos que o desenvolvimento e o refinamento tecnológico desse ramo da medicina têm contribuído bastante para este elevado número; contudo, seria um grande erro desconsiderar os determinantes socioculturais que mobilizam esta busca. $\mathrm{Na}$ sociedade contemporânea, o enquadramento nos padrões do culto da beleza tem encorajado a procura da cirurgia como solução rápida de suas insatisfações ${ }^{4}$.

0 imaginário coletivo do ocidente pós-moderno é permeado pela cultura narcísica, na qual o desejo de onipotência conduz a investir na busca do sucesso individual que atualmente tem a sua materialização no corpo ${ }^{5}$.

Além da supervalorização dajuventude como um bem em si mesmo, acrescentou-se a ideologia de um corpo não só jovem, mas também portador de medidas ideais. $\mathrm{Na}$ pós-modernidade, as representações sociais de um corpo magro, belo e jovem viraram mandamentos ligados à idéia de sucesso. Assim, o sacrifício exigido para modelar do corpo é compensado idealmente pela crença de um sucesso futuro.

No nosso país, a população feminina adolescente ejovem adulta éa mais atingida pelas crenças de que o corpo é infinitamente maleável. Por este motivo, a cirurgia estética não é mais um procedimento associado somente à correção de marcas do envelhecimento ou deformações inatas; percebe-se o crescimento do número de muIheres jovens que buscam a cirurgia estética.

N essa busca da adequação aos padrões socialmenteconstruídos e potencializados pelos meios de comunicação, estabelecidos pela valorização da estética, tem-se preterido a própria saúde.

Os limites do corpo e da psique são extrapolados no esforço imitativo de modelos quase sempreirreaise inatingíveis, muitos criados eajustados por técnicas de manipulação da imagem, pelo uso dos aparatos cosméticos e das técnicas de mudança corporal em geral. As práticas sociais nocivas incluem regimes al imentares radicais e frequentemente irracionais, lesões corporais pelo excesso de exercícios físicos, danos à saúde pelo uso deanabolizantes ou medicamentos para emagrecer (anorexígenos), distúrbios deimagem que acompanham as bulimias e anorexias, além de uma banalização das intervenções estéticas. No caso das cirurgias estéticas, as possibilidades de infecção, problemas com a anestesia, hemor- 
ragias, cicatrizes e outros problemas são minimizados e pouco divulgados. 0 sofrimento do pós-operatório e os riscos de todo processo cirúrgico são justificados pelo culto à beleza.

N este contexto, realizamos esta pesquisa, cujo objetivo foi compreender as crenças, atitudes, percepções e processos culturais subjacentes às narrativas de universitárias, submetidas à cirurgia estética, ecirurgiões plásticos, a partir da perspectiva da promoção da saúde.

\section{M etodologia}

A metodologia utilizada nesta pesquisa foi qualitativa. Assumimos queo nosso interessenas percepções de um grupo, restrito embora representativo de pessoas, justifica este tipo de abordagem ligada às percepções simbólicas e socialmente construídas.

Além disso, concordamos com Yin ${ }^{6}$, que sugere que, em situações nas quais não conseguimos diferenciar o fenômeno em questão de seu contexto, o estudo de caso adequa-se de forma ideal ao método de busca de um conhecimento circunstanciado a respeito deum tema. A riqueza e complexidade da situação em estudo remete à presença de um grande número de variáveis, ao uso de várias fontes de dados ea diferentes estratégias a se utilizar para o desenho de pesquisa e para a análise. Assim, além de qualitativo, nosso método incluiu o estudo de caso.

No nosso estudo, realizou-se um estudo de caso exploratório, quebuscou suscitar questões e hipótese para posteriores pesquisas e, ainda, procurou-se realizar uma descrição o mais completa possível da situação em seu contexto sociocultural, caracterizando um estudo de caso descritivo ${ }^{7}$.

Os participantes da pesquisa compuseram doisgrupos desujeitos: jovensuniversitárias (quatro participantes) e cirurgiões plásticos (quatro participantes).

Com o intuito deresguardar a identidadedos participantes, atribuímos nomes de deuses aos cirurgiões (Zeus, Dioniso, Apolo e Eros), visto que em nossa sociedade eles são, muitas vezes, tidos como salvadores e milagreiros; e nome de deusas às jovens (Afrodite, D eméter, Hera e Atena), pois, por meio da cirurgia estética, elas buscam transformar-se em mulheres bonitas, sedutoras e poderosas como as deusas.

Pelo fato da cirurgia estética ser maisfrequente entre as mulheres, escolhemos esse grupo como mais representativo. As universitárias selecionadas para o estudo tinham idade entre 18 e 29 anos e pertenciam à classe média e média alta. Das quatro participantes, somente uma era casada (Deméter) e não residia com os pais; as demais eram dependentes da família e todas já haviam se submetido a mais de uma cirurgia estética. Afrodite (22 anos) fez cinco cirurgias, Atena (23 anos), Deméter (29 anos) e Hera (22 anos) passaram por dois procedimentos cirúrgicos. Todas as entrevistadas estavam com alta clínica da cirurgia estética e como resultado cirúrgico tinham alcançado o seu ponto máximo na perspectiva médica.

A opção por trabalhar com jovens mulheres universitárias deve-se ao fato deeste grupo apresentar dois fatores considerados relevantes para o estudo. 0 primeiro érelativo à redução significativa da faixa etária de mulheres que se submetem à cirurgia estética, prática queatéal guns anos atrás era associada a idades mais avanças em virtude do envel hecimento, através de procedimentos cirúrgicos para correção de marcas do tempo. Atualmente, o número de cirurgias estéticas vem aumentando consideravelmente entreos jovens, o que desperta nosso interesse na investigação das motivações desta faixa específica de idade de 18 a 29 anos.

O segundo fator, a delimitação pelo nível de superior de escolaridade, deve-se ao interesse em se trabalhar com um grupo que supostamente tinha uma maior possibilidade de acesso à informação, além de potencial para o desenvolvimento de análises críticas, a despeito detrabalhos que mostram que, mesmo em futuros profissionais da saúde, a força do ideal estético socialmente construído prevalece ${ }^{8}$. Os médicos selecionados participaram dos procedimentos cirúrgicose póscirúrgicos das universitárias e trabalham diretamente com cirurgia plástica do tipo estética.

As participantes foram selecionadas através de uma clínica na qual estas realizaram drenagem linfática após os procedimentos cirúrgicos; os médicos foram indicados pelas universitárias e entrevistados em seus consultórios e hospitais nos quais trabal ham. A coleta de dados aconteceu no primeiro semestre de 2007.

N esteestudo, utilizamos como estratégia para o processamento e análise dos dados coletados 0 conceito de representações sociais, como possibilidade de compreensão da cirurgia estética como um ato que visa alterar o corpo, mas um corpo socialmente construído e assim investido de um simbolismo que o precede.

O corpo está encampado pela vida simbólica do espírito humano, por um sistema simbólico, responsável por um trabalho de taxonomia psi- 
cossociológico e por uma classificação precisa. Esse trabalho de taxonomia remonta às formas primitivas de classificação das sociedades, responsáveis pela ordenação do mundo e pela criação das categorias de enten dimento e de explicação desse mundo. Elas são oriundas de uma realidade sui generis de cada sociedade, realidade historicamente dada. Estas formas primitivas e primordiais são as representações coletivas, tradição elaborada por Durkheim.

O conceito de representações em Durkheim baseia-se em três princípios básicos: a base material, chamada demorfologia social, causa econforma as idéias, que assumem uma autonomia relativa em relação às condições materiais da sociedade; as representações sociais são coletivas e sui generis, portanto, objetivas por si mesmas, pois são conformadas historicamente e as repre sentações coletivas exercem coerção sobre os indivíduos e, apesar de sofrerem suas ações, independem desses indivíduos.

As representações coletivas que exprimem a sociedadetêm um conteúdo intei ramentediferente das representações puramente individuais e as primeiras acrescentam muita coisa às segundas. Para Durkheim ${ }^{9}$, De fato, o que as representações coletivas traduzem éa maneira pela qual o grupo se pensa em suas relações com os objetos que o afetam. Ora o grupo é constituído de maneira diferente do indi víduo eas coisas queo afetam são de uma outra natureza. As representações, que não exprimem nem os mesmos assuntos nem os mesmos objetos, não poderiam depender das mesmas causas. Para compreender o modo como a sociedade representa a si mesma e o mundo que a circunda, é a natureza da sociedade, e não aquela dos indivíduos, que de vemos considerar. Os símbolos com os quais ela se pensa mudam pari passu o que ela é.

As representações coletivas são o produto de uma imensa cooperação que se estende no espaço e no tempo. Apesar de não ser um conceito recente, uma teoria das representações sociais só se desenvolveu nas últimas décadas, sobretudo dentro da vertente mais sociológica da psicologia social. Essa retomada, realizada pelo viés da sociologia, ganhou força com o estudo de Serge M oscovici, La psychanalyse: son image et son public, em 1961. Ao aprofundar uma análiseno campo da sociologia do conhecimento sobre a psicanálise, esse autor substitui o conceito de representação coletiva por representação social.

Farr ${ }^{10}$ aponta que M oscovici julga mais adequado, num contexto moderno, estudar repre sentações sociais do que estudar representações coletivas. 0 segundo conceito era um objeto de estudo mais apropriado num contexto de sociedades menos complexas, queeram do interesse de Durkheim. As sociedades modernas são caracterizadas por seu pluralismo e pela rapidez com que asmudançaseconômicas, políticas eculturaisocorrem. A aplicação do conceito dentro do campo da saúde é que podemos compreender várias facetas do adoecimento, da saúde, da mortee das concepções subjetivas do indivíduo que interferem em seu processo de adoecimento e de cura.

As representações possuem um caráter de reflexo das estruturas sociais, remetidas à forma de pensar de todo um grupo ou sociedade de indivíduos mas, também um caráter ativo de ação, de mudança e de transformação, haja vista que as nossas concepções sobre o mundo balizam nossa maneira de agir no espaço social.

Por este motivo, o reconhecimento de narrativas, crenças e processos culturais subjacentes às percepções dos entrevistados na perspectiva da promoção da saúde teve como base esta teoria. Ela nos permitiu uma compreensão da realidade estudada comum aos entrevistados, o que contribuiu na captação de informações e ilustrações a partir das vivências dos participantes em relação à cirurgia estética e ao corpo, porquanto compreendemos o corpo como uma construção individual esocial. Pudemos anal isar eperceber, por meio dos discursos, as representações sociais orientadoras do comportamento, no caso em questão, a cirurgia estética. Dessa forma, concordamos com Brito et al. ${ }^{11}$ quando afirmam que as representações sociais fazem parte do sistema simbólico que produz o conhecimento sobre 0 mundo, atribuindo significado à realidade, eatravés dessa rede simbólica desentidos, épossível pensar o mundo de certas práticas sociais.

Os nossos discursos são construídos por representações sociais sobre o mundo e sobre nós mesmos; por isso, com as entrevistas, tivemos a oportunidade de reconhecer conteúdos ideológiCos, crenças e val ores na fala dos entrevistados sobre o tema proposto; esses conteúdos formaram as representações sociais sobre o corpo, a cirurgia estética ea saúde. Assim, as falas das entrevistadas foram usadas de forma sistemática como modo de ilustrar e, ao mesmo tempo, corroborar as hipóteses teóricas e os achados da pesquisa.

\section{Resultadosediscussão}

A inserção das ciências humanas e sociais no campo da saúde, a par dos movimentos sociais da reforma sanitária brasileira, engendrou o caldo 
sociocultural do qual emergiu o campo de estudo que hoje denominamos Saúde Coletiva. Essas ciências, quenesse processo se constituíram como sociologia da saúde, antropologia da saúde ou medicina social, aportaram um olhar diferenciado sobre os saberes e práticas do fenômeno saú$\mathrm{de}^{12}$, incorporando a subjetividade e as condições sociais aos processos de adoecimento, extrapolando a redução da saúde ao biológico.

A Saúde Coletiva traduz uma concepção que compreende a saúde como um fenômeno social, edeinteresse público, entendida como um direito relacionado à efetivação da cidadania e constituindo-se num dever do Estado. As origens da constituição deste campo remontam do trabaIho político eteórico depesquisadores edocentes deuniversidades ede escolas de saúde pública. 0 trabalho no campo da Saúde Coletiva forneceu suporte a um movimento político, em torno da crise da saúde. Este movimento contribuiu para a formulação de mudanças identificadas como a Reforma Sanitária Brasileira ${ }^{13}$.

A noção de saúde coletiva nasceu na década de setenta com a discussão sobre os determinantes do processo de saúde/doença e a politização de boa parte dos profissionais da área. Por meio da crítica da medicina preventiva e da medicina comunitária , como ela estava sugerida pelos organismos internacionais e a saúde pública tradicional, constitui-se uma massa crítica de saberes e práticas ${ }^{14}$.

Como resultado, a Saúde Coletiva inclui três dimensões: 0 estado de saúde da população, voltado para as condições de saúde de grupos populacionais específicos etendências gerais do ponto de vista cultural, epidemiológico, demográfico e socioeconômico; os serviços desaúde, queabrangem o estudo do processo de trabalho em saúde, avaliam planos, programas e tecnologias utilizadas na atenção à saúde, além da gestão; o saber sobre a saúde, que comporta a produção de conhecimentos, privilegiando os aspectos históricos, sociais, antropológicos e epistemológicos.

0 objeto de atenção deste campo disciplinar reporta ao coletivo, sobretudo os coletivos organizados em busca da saúde. Um coletivo fragmentado, estratificado por classes, por gênero, por etnias, por idade, por condições econômicas. Assumimos uma concepção ampliada ecomplexa sobre a saúde, permeada e influenciada por fenômenos sociais, culturais e históricos. N essa perspectiva, a abordagem do imaginário social sobre o corpo e a construção social das distinções sociais nele baseadas parece ser um tema promissor na área da saúde ${ }^{15}$.

\section{A cirurgia estética}

como um problema de saúde coletiva

A partir deste entendimento, fica mais evidentea compreensão da cirurgia estética no contexto da Saúde Coletiva, pois ela progrediu graças aos avanços da tecnologia médica, mas sobretudo a partir da modificação do paradigma em relação ao corpo ${ }^{16}$.

À medida que a cultura midiática foi tornando-se hegemônica, sobretudo a partir da segunda metade do século XX, o corpo, bem como as suas aparências, tornaram-se protagonistas dos processos de sociabilidade em nossa cultura, acentuando radicalmente seu caráter audiovisual ${ }^{17}$. Esteéum dado relevantena consolidação do valor que a imagem e a aparência passaram a desempenhar na sociedade hodierna.

A vai dade com o corpo era considerada anteriormente como pecado efutilidade, mas passou a ser vista ao mesmo tempo como uma virtude e uma obrigação. Se, graças ao movimento feminista, o corpo libertou-se de suas antigas prisões de procriação e deuso de uma indumentária restrita, hoje é exposto a coerções sociais redobradas em valores morais quanto à beleza estética.

$N$ ão é privilégio da nossa época ter a medicina e suas práticas médicas associada à beleza, especialmente a beleza do corpo. Contudo, em nenhuma outra época o saber médico e o seu discurso tiveram uma relação tão simbiótica com as práticas estéticas. A cirurgia plástica do tipo estética é o fenômeno mais visível; no entanto, áreas como a dermatologia, endocrinologia, oftalmologia, gerontologia, dentre outras, também contribuem com as demandas estéticas ${ }^{18}$.

Em nosso mundo mundializado, em quetudo é mercantilizado, o indivíduo adquiriu a possibilidade de construir seu corpo de acordo com as demandas coletivas e individuais.

0 corpo humano, principalmentedevido aos avanços tecnológicos ecientíficos, representa, na sociedadecontemporânea, um misto entreo inato e o adquirido, pois em nossa cultura é muito difícil a manutenção de características próprias, sejam estas individuais, sejam sociais ${ }^{16}$.

Deacordo com Kehl ${ }^{19}$, o corpo-imagem apresenta-se, atual mente, como determinante da felicidade, não por despertar o desejo ou o amor de alguém, mas sim por se constituir como objeto de amor-próprio, ou seja, como fundamento da auto-estima, a que se reduziram todas as questões subjetivas na cultura narcísica. N estetipo de cultura, o corpo éobjeto de investimento do amor narcísico e a imagem que oferecemos ao mundo 
é reconhecida como a verdade do sujeito, pois dela dependeria a aceitação social. 0 corpo torna-se um escravo que devemos submeter à rigorosa disci plina da indústria da forma, enganosamente chamada de indústria da saúde. Por este corpo, devemos sacrificar o nosso tempo, nossos desejos, nosso dinheiro.

Um fato que contribui para que este corpoimagem seja reconhecido como a verdade do sujeito deve-se às relações interpessoais estarem cada vez mais efêmeras, valorizando a primeira impressão estética.

A aparência ganha função bastante relevante na comunicação, pois em muitos casos o tempo de comunicação interpessoal é curto, acelerado e descontínuo, o quesobredetermina o corpo como meio de expressão do ego e responsável pelo sucesso ou fracasso pessoal. Isto induz à busca de regimes, adornos e processos cirúrgicos com 0 objetivo de se adequar a padrões idealizados.

Além disso, o fato do Brasil ser um país tropical contribui para que a exposição corporal seja mais acentuada, o queintensifica a preocupação e as exigências com o corpo. Em cidades litorâneas como Fortaleza eo Rio de Janeiro, essefenômeno é mais notório, diferente de lugares onde 0 frio não facilita a exposição do corpo: Eu tenho uma clientela muito grande em Juan, na França, a cinco minutos de Paris; tem muitos anos que eu tenho pacientes lá e é interessante que eu nunca fiz uma cirurgia em Juan que fosse escultura de corpo, eu só faço rosto, nariz, olho, ninguém está muito preocupado com o resto do corpo, elas tão muito bem daquele jeito, gordas ou magras, com peito duro ou mole, não estão interessadas, o que importa é 0 rosto delas, este é um detalhe interessante (Zeus).

0 mercado tecnológico da estética, em conjunto com o apelo midiático, forma uma teia na qual as subjetividades são enredadas e levadas a uma procura simbólica do corpo ideal e da beleza imaginária. Essa conjunção publiciza, via fascinação, modelos de beleza que tendem a ocupar 0 limite extremo dessa busca obsessiva, desfigurando, assim, a tênue linha divisória entre o saudável cuidado com o corpo e o sutil movimento de instalação de doenças narcíseas ${ }^{20}$.

No entanto, essa ênfase no cuidado centrado no corpo vem aumentando os problemas em relação à saúde física e emocional, por conta de uma banalização do ato cirúrgico, como revelam as entrevistas: A rinoplastia, na verdade, eu nem tinha muita vontade de fazer não, meu nariz não era feio, mas duas primas minhas fizeram e ficou muito legal; aí eu aperreei uma semana a minha mãee ela deixou, então eu fiz egostei do resultado.
Era assim, isso aqui era reto [nariz] não tinha aquele osso para cima, mas não tinha curva e eu queria fazer a curva e pronto, eu fiz (Afrodite).

$\mathrm{N}$ o começo eu tivemedo, mas acho quequando você tem vontade de fazer vale à pena, entendeu? Não é por causa de um medozinho que você não vai. Não é uma coisa perigosa, anestesia peridural (Hera).

Eu tenho uma amiga que fala assim: "eu vou lá ficar morrendo, suando, me acabando em academia, eu não, surgiu uma gordurinha, vou lá e digo tire aqui, doutor" (D eméter).

A geração que tá vindo atrás da nossa é muito pior na idolatria da beleza, na idolatria da aparência e banalizou mesmo, eu tenho primas de catorzee quinze anos que já falam em fazer cirurgia estética, é uma outra mentalidade (Atena).

Por ser um procedimento que busca a beleza ea decisão defazê-la ser daquele que se submete, a dor sempre transparece nas falas de modo minimizado e eufemizado. Segundo Chataignier ${ }^{21}$, as revistas femininas contribuem bastante na divulgação desta crença na medida em que enfocam, de maneira superficial, o sofrimento como forma de exaltar a beleza; para isso tornam sinônimos prazer e dor na busca de compensações estéticas que irão preencher vergonhas e vazios.

Quando instadas sobre o pós-operatório, as entrevistadas tendiam a discorrer rapidamente sobre esta fase; muitas ressaltaram que, mesmo este momento sendo difícil, o sacrifício valia a pena: Eu estava um pouco confusa, estava triste, estava querendo sumir, tinha acabado um namoro recente, então pensava, vou fazer para melhorar e não tive resultado até o dia em que eu parei e fui cuidar da minha mente (Atena).

No pós-operatório, você se sente muito mal, a do nariz eu melembro que eu pensei, ai meu Deus, por que eu fiz? Tudo o que eu queria era o meu nariz de volta, arrancar esse gesso, esse inchaço, 0 olho fica desse tamanho todo roxo. No pós-operatório, tanto na cirurgia do nariz como na do silicone, tudo que você quer é seu peito e seu nariz de volta antes mesmo de acabar a dor; mas também tudo dura muito pouco tempo, no nariz dura os dez primeiros dias e na do silicone oito, dez primeiros dias, mas depois você se esquece da dor (Afrodite).

Primeiro dia eu nem senti direito, senti quando eu vim pra casa, masnão foi nada demais, senti um pouquinho de dor, mas nada que você fique sem aguentar, eu sofri muito mais quando operei a garganta do que quando fiz a lipo (Hera).

Outras relatam justamente o contrário: A lipo é uma cirurgia muito agressiva, então eu senti 
muita dor na lipo, eu me arrependi muito de ter feito na época, hojeem dia não, como eu tirei muito pouco, eu acho que quanto menos vocêtira pior é, ou então depende. Por um lado ébom porquequando vocêtem um limiar de dor muito sensível, tudo o seu corpo acusa, algumas pessoas têm derrame interno e o corpo não acusa, mas por outro lado eu sofri muito, na primeira semana foi horrível, horrível. Eu sentia muita dor e tive que fazer punção, eu não conseguia dormir, horríveis, horríveis mesmo (Atena).

Além dos riscos físicos de qualquer operação, na cirurgia estética, problemas emocionais podem ser atribuídos ao corpo físico, transportando ao ato cirúrgico questões emocionais de uma imagem corporal distorcida, ou seja, bem diferente do esquema corporal, tirando dealguns pacientes o suporte ou apoi o físico para suas queixas e, como consequência, leva-o a eleger outra parte do corpo ou a um agravamento do seu quadro psíquico, pois incisões vão além da superfície cutânea, atingindo também a psique, acarretando, às vezes, mudanças súbitas e profundas no caráter e na personalidade².

A cirurgia estética podemudar tudo, tanto para o lado positivo como para o negativo, eu acredito que essa cirurgia opera muito mais a cabeça da pessoa do que o próprio órgão em si, então se as pessoas atribuem todos os insucessos da vida àquilo que ela está buscando corrigir, a mulher que acha que o marido foi embora porque ela está com a mama flácida, ou está com a barriga gorda, ou alguma coisa desse tipo, então essas pessoas têm uma chance muito grande de se frustrar, das cirurgias não corresponderem ao queelas buscam (Dioniso).

A insatisfação pode ser um resultado da cirurgia, caso a expectativa não corresponda às possibilidades reais. Tais desejos podem estar associados a fantasias, conscientes ou não, de que se tornar fisicamente parecido com um modelo ideal tornaráa pessoa socialmente reconhecida como bela e bem-sucedida.

Outra fonte de insatisfação é não reconhecer e não aceitar o seu novo corpo, pois a imagem corporal ainda não foi modificada. É importante que uma nova inscrição psíquica seja feita para que a pessoa fique bem com a sua nova imagem. Para isso, é significativa a ocorrência do que a psicanálise chama de trabalho de luto, que consistena retirada de investimento libidinal do objeto perdido e o reinvestimento em outro objeto, no caso em questão, na nova forma do corpo ${ }^{22}$. Caso isso não aconteça, podemoster o queFreud denominou melancolia, poiso sujeito não desinveste 0 objeto, mas se identifica com ele, trazen- do para si os sentimentos negativos que tinha em relação ao objeto perdido. Vale ressaltar que este objeto pode ser um trabalho, uma pessoa, uma parte do corpo.

Ao recorrem a procedimentos cirúrgicos ou outras formas de alteração corporal, as pessoas podem melhorar sua imagem e auto- estima, mas correm um sério risco de entrarem em uma disfunção mental ligada ao corpo ${ }^{23}$. Assim traduz em metáfora um cirurgião: Q uando você compra um vidro de perfume, você basicamente compra a ilusão, porque acha que com aquele aroma quevai passar a exalar está se tornando uma pessoa agradável ; vocêsabeque, muitas vezes, pelo menos com perfumes muito ativos, consegue-se 0 resultado exatamente oposto. Então temos que traçar um perfil psicológico dessas pessoas muito bem feito para que a cirurgia tenha chance de resultar em coisas que realmente melhorem a auto-estima da paciente (Dioniso).

A cirurgia estética possui um impacto na saúde. Assim, faz-se necessária a substituição da visão biomédica por outra cuja compreensão da saúde seja a de um complexo processo de funcionamento sistêmico e integrado do somático e do psíquico, no qual ambos dialeticamente se influenciam.

Além disso, a cirurgia estética, atualmente, é considerada um fenômeno coletivo, considerando-se os el evados números deste procedimento, ou seja, não é mais algo pontual, monopólio de alguma classe social, gênero ou idade. Observamos que, dada a sua expressividade, podemos considerá-la como uma prática coletiva cuja demanda se amplia a cada ano.

Com 0 aumento de procedimentos, também crescem os riscos à saúde da coletividade, pois quanto mais cirurgias estéticas são realizadas, mais aumentam os problemas decorrentes detais procedimentos. $\mathrm{Na}$ representação comum, são os fatores positivos, como sentimentos de aceitação e enquadramento, que são relacionados à cirurgia estética; mas casos deinsatisfação com o resultado, complicações cirúrgicas que interferem na saúde e no bem-estar também ocorrem.

Por conta disso, concordamos com Vieira ${ }^{24}$ quando argumenta que, em relação à cirurgia estética, não se deve perder de vista o fato de ser esta uma especialidade médica, ou seja, da área da saúde; por isso, não deve prescindir do seu compromisso com o bem-estar integral do paciente, o médico não pode minimizar do seu compromisso ético com a saúde.

Duranteas entrevistas com os cirurgiões plásticos, perguntamos sobre os critérios de avalia- 
ção do paciente para a decisão cirúrgica. Todos os informantes descrevem sobre a importância de uma avaliação com os futuros clientes.

O scritériossão os seguintes: existea surgeryholic, esta é uma expressão americana, aquela paciente queélouca por cirurgia, então ela passa o dia todinho inventando cirurgia, ela quer se operar porque ela quer, porqueela atribui todos os problemas da vida dela a alguma coisa eesseéum paciente perigoso porque quando você termina uma cirurgia, quando vocêestá terminando de operar, ele inventa outra, inventa outra, inventa outra, e assim vai... Esse é um paciente que não pode. Pacientes com expectativa que diz "eu quero ficar igual a Camila Pitanga" ou "então eu vim me operar aqui porquemeu marido atualmentesó ta querendo andar com os brotinhos, dançando no final de semana etudo, então eu vim aqui para poder competir com essas meninas que o meu marido anda andando" (Dioniso).

Existem cirurgias que você não faz, quando a paciente tem uma expectativa muito grande, uma senhora de setenta etantos anos, por exemplo, em uma cirurgia de rosto, ela disse" "eu vim fazer porque eu quero ficar mais bonita". Só que é uma senhora quenão éatraente. Essa cirurgia não é para ficar bonita, é para rejuvenescer, então você tem que dar um jeito de não operar essa paciente se ela não entender isso aí (A polo).

Percebemos que todos os médicos entrevistados ressaltaram que procuram investigar sobre a saúdefísica para a realização de uma cirurgia, mas também ressal tam a importância de um olhar atento para as expectativas dos pacientes, visto que muitos recorrem às cirurgias com ilusões vendidas pelos apelos da mídia. Além disso, comentaram sobre a importância da não realização de al gumas cirurgias pela possibilidade de problemas futuros.

Percebemos que muitas das reações indesejáveis do pós-operatório poderiam ser evitadas com informações e esclarecimentos prévios, integrando o trabal ho da cirurgia com o de educação em saúde ${ }^{25}$.

A palavra problema, neste contexto, possui 0 sentido de algo que deve ser considerado pelo campo da Saúde Coletiva, poisa cirurgia estética como registramos anteriormentenão émais uma prática de poucos, mas coletivizada e ligada a todo um arbitrário cultural e possui um impacto significativo na saúde da coletividade.

\section{Consideraçõesfinais}

A discussão sobre a relação corpo-alma tem sido recorrentena história humana, especialmentenas sociedades ocidentais. Reconhecemos que a valorização do corpo, do belo e da experiência esté tica não é um mérito da modernidade nem das sociedades modernas, visto queci vilizações antigas já demonstravam, por meio da artee de narrativas, o valor atribuído à beleza.

Contudo, nas sociedades pós-industriais, 0 corpo e seus atributos, especialmente a beleza, adquiriram uma centralidadesem precedentes na história. Neste contexto, o aspecto estético do corpo exerceum papel muito importante na formação da imagem corporal, pois esta está associada não somente ao interessesexual, mastambém às demandas profissionais, dentre outras.

A presentamos nestetrabal ho a maneira como um procedimento médico com objetivo estético se relaciona com a saúde. Concluímos que, para essa compreensão, é preciso um entendimento ampliado de saúde, pois se o corpo é algo perpassado pelo simbólico, a saúde e a doença também são, pois o que é considerado saudável em uma cultura pode ser interpretado como patológico em outras.

Mulheres ocidentais acreditam ser extremamente saudável o autocuidado e modelamento do corpo por meio de cirurgias; todavia, algumas mulheres do orienteacreditam queessa obstinação pela beleza física seja tão sufocante como julgamos ser o xador, a longa veste negra que cobre as muçulmanas.

A cultura ocidental vem perdendo 0 apego às tradições, às religiões; o discurso que impera, conduz e organiza as experiências corporais é 0 discurso científico, apropriado pelos interesses do capital e cujo uso mediático, apoiando-se no discurso médico, reforça suas fundamentações para os usos comerciais do corpo.

Atualmente, ainda somos marcados por uma herança patriarcal que valoriza características como controle, autoridade, competição, supremacia do pensamento lógico e discriminação da multiplicidade. Em razão desta val orização, vivemos numa cultura de produção em massa e padronização, o que nos estimula a uma desassociação das emoções para uma adaptação extrema ao coletivo, deixando adormecida a própria subjetividade esingularidade. Esta afirmação parece 
contraditória quando nos deparamos com uma sociedadeindividualista, hedonista enarcísica. No entanto, não devemos confundir uma pessoa que preza o individual acima do coletivo, obedecendo a uma tendência ironicamente coletiva, com uma pessoa que reconhece a sua singularidade, mas também o seu pertencimento a um coletivo e por isso não o nega e não vira vítima deste.

A tendência contemporânea é de desprezar questões como a pluralidade, 0 autoconhecimento, a imaginação, os sentimentos, a intuição, a cooperação, os limites do ego e a introspecção. Além disso, o corpo tem assumido a materialização destas habilidades esquecidas, tornando-se 0 depósito de satisfações e insatisfações e assumindo o lugar anteriormente ocupado pela "alma".

0 preço desse esquecimento éparadoxalmente 0 excessivo autocuidado. Não queremos com isso condenar as cirurgias estéticas, mas sim pontuar que muito da excessiva busca por cirurgias ultrapassa o caráter de um melhoramento do corpo para uma busca sem fim de modelos propostos pela sociedade do simulacro, onde as pessoas alienadas de si mesmas perdem-se nessa procura.

Constatamos que existe uma medicalização da beleza estética, com os grupos médicos interessados assumindo os padrões biomédicos de normalidade e desvio como forma de promover um número crescente de intervenções sobre 0 corpo dos pacientes, sem considerar o caráter social da definição de beleza ${ }^{26}$.

Quisemos despertar a necessidade de estudos e pesquisas que visem alavancar 0 empoderamento e 0 autocuidado com o corpo, não somente no sentido do embelezamento, mas também do autoconhecimento. N essa vertente, a cirurgia estética poderia sim ser promotora de saúde, deacordo com as percepções deal guns entrevistados da pesquisa. Como o culto ao corpo é um fenômeno cultural e a busca da cirurgia preenche não somente um ideal de perfeição, mas também uma adequação às crenças e processos culturais. Dessa forma, a cirurgia estética pode contribuir para um bem-estar e um sentimento depertencimento.

Esses registros denotam que, em nossa cultu$\mathrm{ra}$, as mulheres buscam intensamente um corpo ideal; no entanto, estão cada vez mais atadas a uma percepção sinônima de corpo físico, embora saibamos que ele compreende uma totalidade mais ampla e que suas outras dimensões precisam ser contempladas, como a expressividade, 0 movimento e a capacidade de sentir, dentre outras, tão sedutoras e valiosas quanto o efeito esté tico. Enfim, urgente se faz contribuir para que a idéia de corpo ideal transcenda a materialidade do físico em direção a uma concepção integral e harmoniosa do ser humano em sua plenitude.

\section{Colaboradores}

VCLV Leal participou da elaboração do projeto, analisou os dados eredigiu o manuscrito inicial. AM F Catrib e RF de Amorim participaram da elaboração da pesquisa e elaboração da redação final. M A M ontagner discutiu o trabalho, revisou e elaborou a versão final. 
Referências

1. Pitanguy I, Salgado F, Radwanski HN. Princípios da mamoplastia redutora: experiência na $38^{\mathrm{a}}$ enfermaria da Santa Casa da Misericórdia do Rio de Janeiro. Acta M edica M isericordiae 1999; 2(2).

2. Pitanguy I. Aspectos filosóficos e psicossociais da cirurgia plástica. In: Mello Filho J, organizador. Psicossomática hoje. Porto Alegre: Artes M édicas; 1992. p. 264-72.

3. Sociedade Brasileira de Cirurgia Plástica. Pesquisa sobre a demanda. [acessado 2006 ago 29]. Disponível em: http://ss1271.locaweb.com.br/cirurgia plastica2membros/gallup05.gif

4. Edmonds A. No universo da beleza: notas de campo sobre a cirurgia plástica no Rio de Janeiro. In: Goldenberg M, organizador. Nu e vestido. Rio de Janeiro: Record; 2002. p. 189-262.

5. Vasconcelos N, Sudo I, Sudo N. Um peso na alma: o corpo gordo e a mídia. Revista M al-Estar e Subje tividade 2004; 4(1):65-93.

6. Yin RK. Applications of Case Study Research. $2^{\text {nd }} \mathrm{ed}$. Thousand Oaks: Sage; 2003.

7. Yin RK. Case Study Research. N ewbury Park, CA: Sage; 1994.

8. Bosi MLM, Luiz RR, Morgado CMC, Costa MLS Carvalho RJ. Autopercepção da imagem corpora entre estudantes de nutrição: um estudo no município do Rio de Janeiro. J bras psiquiatr 2006; 55 (2):108-113.

9. Durkheim É. Les règles de la méthode sociologique: étude sociologique. 1894 [acessado 2004 set 20]. Disponível em: http://classiques.uqac.ca/classiques/

10. Farr RM. Representações sociais : a teoria e sua história. In: Guareschi PA, Jovchelovitch S, organizadores. Textos em representações sociais. Petrópolis: Vozes; 1994. p. 31-59.

11. Brito HB, Catrib AMF. Representação social e subjetividade do adoecer psíquico. Estud psicol ( $\mathrm{N}$ atal) 2004; 9 (2):285-296.

12. M ontagner MA. Pierre Bourdieu e a saúde : uma sociologia em Actes de la recherche en sciences sociales. Cad Saude Publica 2008; 24(7):1588-1598.

13. Escorel $\mathrm{S}$. Reviravolta na saúde. Rio de Janeiro: Fiocruz; 1999.

14. Donnangelo MCF, Pereira L. Saúde e Sociedade. São Paulo: Duas Cidades; 1976.
15. M ontagner M Â. Pierre Bourdieu, o corpo e a saúde: algumas possibilidades teóricas. Cien Saude Colet 2006; 11(2):515-526.

16. Pires BF. 0 corpo como suporte da arte. São Paulo: Senac; 2005.

17. Amorim R. 0 imaginário do corpo masculino na musculação [dissertação]. Fortaleza (CE): Universidade Federal do Ceará; 1995.

18. Amorim R. Império da magreza: o imaginário do corpo feminino na pós-modernidade [tese]. Fortaleza (CE): Universidade Federal do Ceará; 2001.

19. Kehl M. Com que corpo eu vou. In: Kehl M, Bucci $E$, organizadores. Videologias: ensaios sobre a televisão. São Paulo: Boitempo; 2004. p. 174-179.

20. Bosi M LM, Andrade A. Transtornos do comportamento alimentar: um problema de saúde coletiva. Cadernos de Saúde Coletiva 2004; 12(2):197-202.

21. Chataignier G. Vintage: a cultura de segunda mão e o resgate cultural da memória brasileira. In: CastiIho K, Galvão D, organizadores. A moda do corpo e o corpo da moda. São Paulo: Esfera; 2002. p. 9-22.

22. Quinet A. Psicose e laço social. Rio de Janeiro: Jorge Zahar; 2006.

23. Queiroz RS, Otta E. A beleza em foco: condicionantes culturais e psicobiológicos na definição da estética corporal. In: Queiroz RS, organizador. 0 corpo do Brasileiro: estudos de estética e beleza. São Paulo: Senac; 2000. p. 13-66.

24. Vieira KMF. O corpo da mulher em correção: subjetividade e cirurgia estética [dissertação]. Fortaleza (CE): UNIFOR; 2006.

25. Barroso FL. O paciente e seu cirurgião In: M ello Filho J, organizador. Psicossomática Hoje. Porto Alegre: Artes M édicas; 1992. p. 259-262.

26. Poli Neto P, Caponi SNC. A medicalização da beleza. Interface (Botucatu) 2007; 11(23):569-584.

Artigo apresentado em 29/04/2008

A provado em 29/07/2008 